\title{
REACTOR IN-CORE REGENERATIVE NEUTRON DETECTORS INTERIM DEVELOPMENT REPORT
}

C. N. Jackson, Jr.

\section{OCTOBER 1967}

\section{AEC RESEARCH \& DEVELOPMENT REPORT}

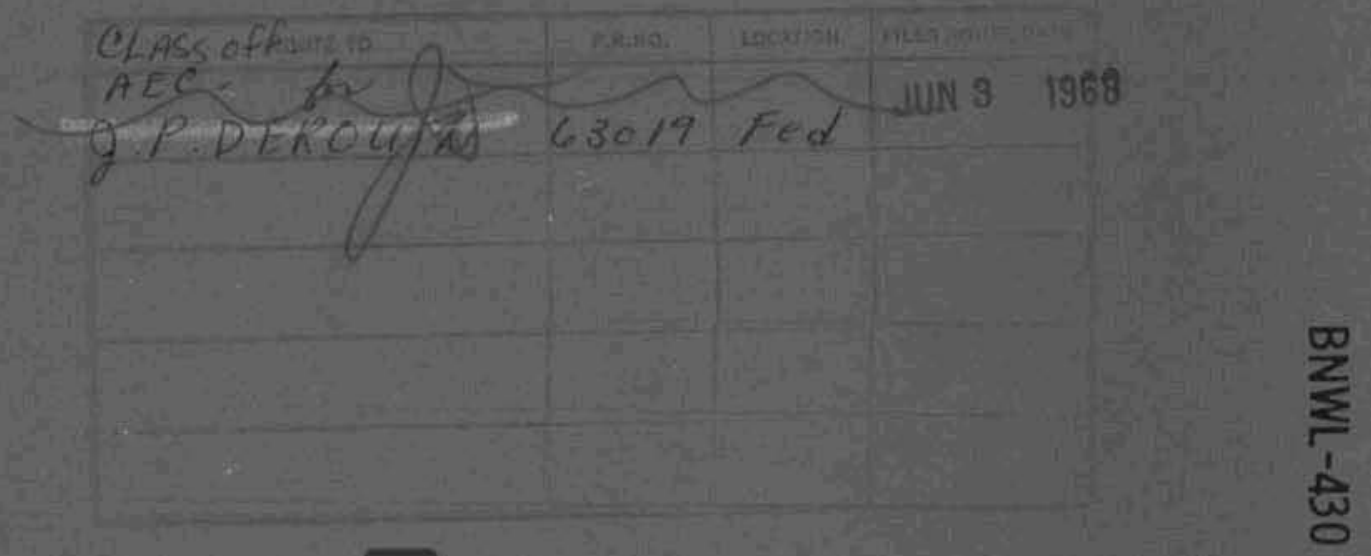




\title{
LEGAL NOTICE
}

This report was prepared as an account of Government sponsored work. Neither the Unifed States, ner the Commission, nor any person acting on behalf of the Commission:

A Mokes any warranty or representation, expressed or implied, with respect to the accurocy, completeness, or usefulness of the information contained in this report, or that the use of any information. opporatus, method, or process diselosed is this teport may not infringe privately owned rights; ar

B. Assumes ony liabilities with respect to the use of, or far damoges resulting from the use of any information, opporatus, method, or process disclosed in this report.

As used in the above, "person acting on behalf of the Commistion" includes any employee or contractor of the Commission, or employee of such contractor, to the extent thot such employee on contractor of the Commission, or employee of such contractor prepares, disseminates, or provides access to; any Information pursuant to his employment or contract with the Commission, or his employment with such confractar.

\author{
PACIFIC NORTHWEST LABORATORY \\ RICHLANO, WASHINGTON \\ operated by \\ BATTELLE MEMORIAL INSTITUTE \\ for the
}

UNITED STATES ATOMIC ENERGY COMMISSION UNDER CONTRACT AT(45-1)-1830 


\section{ERRATA}

Page 4, Line 2

$$
\text { Change } 4 \times 10^{15} \text { to } 5 \times 10^{14} \text {. }
$$


BNWL -430

UC-37, Instrumentation

\title{
REACTOR IN-CORE REGENERATIVE NEUTRON DETECTORS \\ INTERIM DEVELOPMENT REPORT
}

\author{
By \\ C. N. Jackson, Jr. \\ Instrumentation Section \\ Applied Physics and Electronics Department
}

October 1967

2.67

Pacific Northwest Laboratory

Richland, Washington 


\section{Printed in the United States of America} Available from

Clearinghouse for Federal Scientific and Technical Information National Bureau of Standards, U.S. Department of Commerce Springfield, Virginia 22151

Price: Printed Copy $\$ 3.00 ;$ Microfiche $\$ 0.65$ 


\section{TABLE OF CONTENTS}

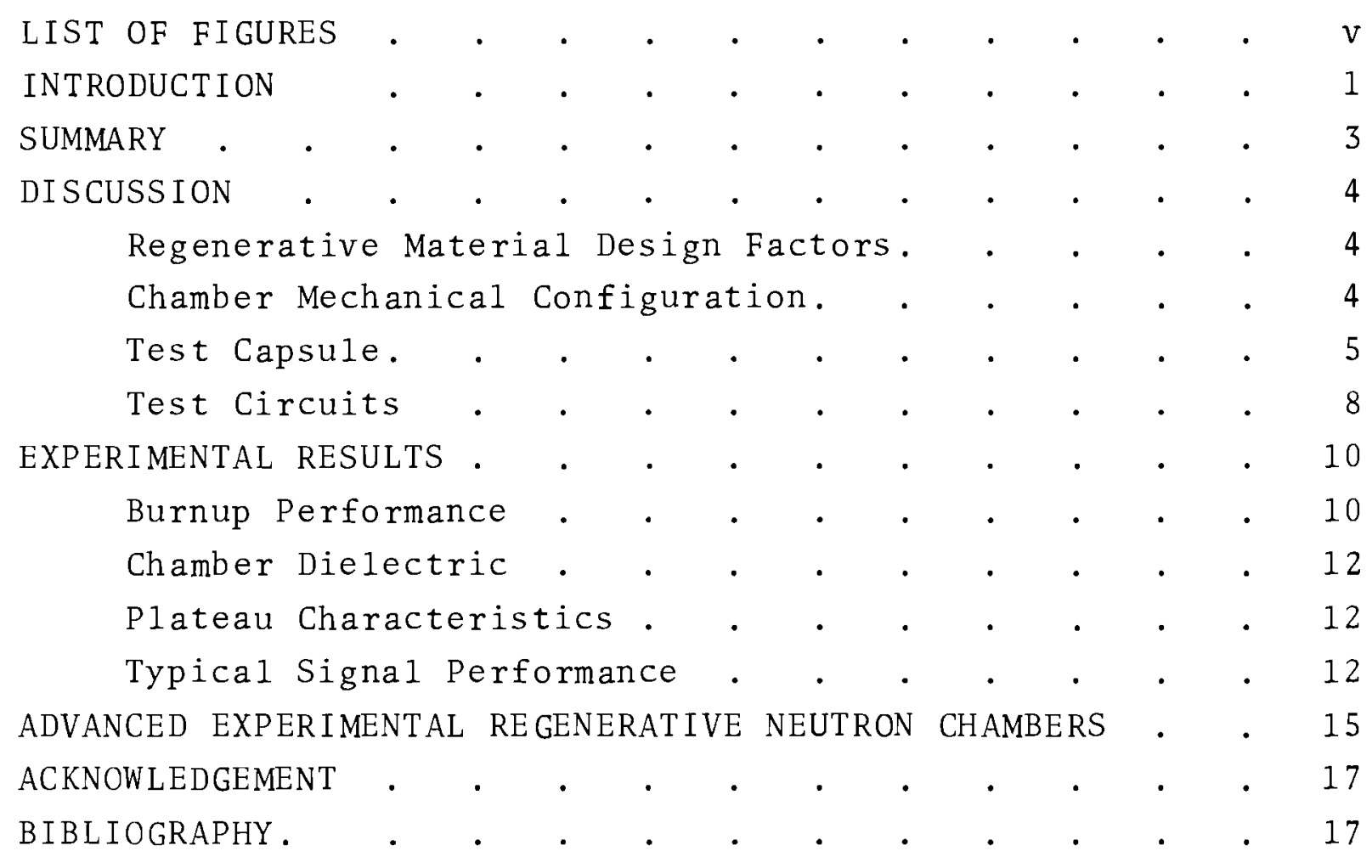




\section{$\underline{\text { LIST OF FIGURES }}$}

1 Design Details of Experimental In-Core Regenerative Neutron Chamber

2 Regenerative Chamber Test Capsule

3 Instrumentation Circuit for I-V Plateau Curve

4 Effect of In-Core Exposure on Chamber Sensitivity

5 Effect of In-Core Exposure on Regenerative Chamber Plateau Characteristics

6 Typical Saturation Curves

7 Typical Regenerative Chamber Recorded Signal Output 


\section{REACTOR IN-CORE REGENERATIVE NEUTRON DETECTORS \\ INTERIM DEVELOPMENT REPORT}

C. N. Jackson, Jr.

\section{INTRODUCTION}

Rapid burnout of nuclear reactor in-core neutron flux detectors at high thermal flux levels and other limitations of existing detectors are well recognized. A candidate tech nique for considerably extending the useful, in-core lifetime of neutron sensing detectors is the employment of regenerative materials within an ionization chamber, for example. The regenerative material comprises both fertile and fissile atoms, where the fissile atoms cause generation of an electrical signal proportional to the thermal neutron flux level. In this method, appropriate combinations of isotopes, ${ }^{234} \mathrm{U}$ and $235 \mathrm{U}$ in this case, are used such that the fertile atoms transmute, by absorption of thermal neutrons, to fissile atoms at approximately the same rate as the fissile material depletes. Thus, long-term detection sensitivity remains relatively constant for extended nuclear reactor in-core exposure periods.

This report describes nuclear reactor in-core investigations at high thermal neutron flux levels being conducted under the sponsorship of the United States Atomic Energy Commission Division of Reactor Development and Technology. These experiments are determining the operational and 1 ifetest characteristics of developmental, regenerative neutron flux detectors utilizing an appropriate mixture of ${ }^{234} \mathrm{U}$ and ${ }^{235} \mathrm{U}$ as the coating material within the detector. With such in-core detectors, desirable optimization of reactor performance can be achieved by continuously monitoring the detector output in order to provide useful data concerning the spatial distribution and level of neutron flux throughout the reactor core. The obtained flux information yields detailed 
knowledge of core conditions and thus allows the fuel elements to be irradiated at an optimum rate with assurance that critical material design 1 imitations will not be exceeded. Economy in reactor operating costs and improved operational safety can thus be obtained by using in-core flux monitoring.

Currently, ${ }^{235} \mathrm{U}$ fission chambers and self-powered rhodium detectors (1) are two typical devices utilized for in-core neutron flux monitoring. The fission chamber suffers from an excessively rapid burnup characteristic which results in a significant reduction in output signal strength during a reasonable 1 ife expectancy. With ${ }^{235} \mathrm{U}$ as a target materia1, $10 \%$ of the emitter atoms are burned up in 17 days at a possible commercial reactor thermal neutron flux leve 1 of $1 \times 10^{14} \mathrm{nv}$. Relative sensitivity may significantly change during one reactor operating cycle, thus requiring frequent replacement of detectors. Compared with fission chambers, the electrical signal strength of the rhodium device is smaller and correspondingly more difficult to use.

Earlier regenerative detector reports $(2-4)$ describe initial phases of this program, including the initial test where two experimental detectors were first installed in-core in a graphite-moderated, light water cooled Hanford production reactor. For these regenerative detectors, the optimum concentrations for the two isotopes were determined to be $90.1 \%$ $234 \mathrm{U}$ and $9.9 \%{ }^{235} \mathrm{U}$ by a calculational experimental technique $(5)$ involving computer analysis. Formulation of the emitter material was matched to the in-core requirements. Extended life and operational characteristics of these regenerative chambers observed during the subsequent sustained in-core testing are described and analyzed in this report, and tech nical details are presented for both the detector and capsule design. Future plans are presented for a second in-core test capsule that will feature a more comprehensive test package, 
which includes several types of neutron detectors in order to fully demonstrate, on a comparative basis, the performance of this regenerative detector concept.

\section{SUMMARY}

In order to circumvent the problems of rapid performance degradation and other limitations of nuclear reactor in-core neutron flux detectors operating at high thermal neutron flux levels, development of regenerative ${ }^{234} U-{ }^{235} U$ detectors is being conducted. The sustained, relatively constant sensitivity of two experimental detectors, inserted within the core of a Hanford plutonium production reactor, demonstrated that extension by a factor greater than ten in the useful in-core life can be achieved with a regenerative emitter material as compared to a typical fission chamber. The sensitivity remained within essentially $10 \%$ of a median value throughout an exposure of $5 \times 10^{21}$ nvt for a calculated optimum regenerative emitter formulation of about $10 \% 235_{U}$ and $90 \% 234 \mathrm{U}$. This performance is equivalent to more than ten years operation in a possible nuclear commerical reactor having a neutron flux level of $1 \times 10^{13} \mathrm{nv}$. Typical of fission chambers, these experimental devices exhibited a robust signal strength, prompt response, and a dynamic range of about four decades. The detector sensitivity was about $1 \mathrm{x}$ $10^{-16}$ A per $n v$ for thermal neutron and about $8 \times 10^{-13} \mathrm{~A}$ per $\mathrm{R} / \mathrm{hr}$ for gammas with a chamber sensitive volume one inch in diameter by one inch in length. Noted reductions in chamber dielectric characteristics were attributed to deficiencies in the test chamber vehicle.

To demonstrate the practicality of these regenerative chambers for use in the nuclear industry and to overcome the dielectric problems, a second test capsule has been prepared using commercially fabricated detectors. This capsule will 
be irradiated in the ETR at the National Reactor Test Site in a thermal neutron flux level of about $4 \times 10^{15} \mathrm{nv}$. A comprehensive test package, this capsule includes ten individual detectors and will permit comparative performance evaluation of regenerative, ${ }^{235} \mathrm{U}$, gamma and rhodium beta current devices. The test capsule features chambers of nearly identical design, differing principally in the material contained within the detectors.

\section{DISCUSSION}

\section{REGENERATIVE MATERIAL DESIGN FACTORS}

The optimum regenerative mixture of about $90 \%{ }^{234} \mathrm{U}$ and $10 \%{ }^{235} \mathrm{U}$ utilized in the experimental samples was determined by a MIN of INT computer program. (5) In this calculational method, the isotopic concentrations were optimized to achieve a maximum "useful" lifetime during which the sensitivity remains within $10 \%$ of a median value.

of four potential fertile isotopes, shown in Table I, $234_{U}$ exhibits the most desirable characteristics for use in a regenerative chamber. Briefly reviewing the characteristics, the ${ }^{232}$ Th and $238_{U}(6)$ both have undesirable long half-1ife delay factors and the ${ }^{240} \mathrm{pu}$ with a relatively high cross section would burnup too rapidly. The ${ }^{234} \mathrm{U}$ has desirable prompt response and an effective burnup cross section of about $100 \mathrm{~b}$ that will achieve long life characteristics.

CHAMBER MECHANICAL CONFIGURATION

The detector chamber was designed along conventional fission chamber lines with significant emphasis being placed on the achievement of a maximum neutron to gamma signal ratio. The quantity of fissile emitter coating determines the neutron sensitivity; it is limited ultimately by the self-absorption experienced by the fission recoil products. The regenerative 
$235_{U-} 234_{U}$ emitter coating was plated by electro-chemical deposition on the inner surface of the emitter cylinder. A relatively heavy coating of regenerative material was applied to the emitter to achieve a high neutron sensitivity and a correspondingly high neutron to gamma signal ratio. 'ihis high signal ratio was refiected in the large dynamic range of five decades observed in the neutron sensitivity of the detectors during early phases of the testing. Gradually, the neutron dynamic range dropped to about four decades as the residual gamna background built up in the chamber due to exposure.

TABLE I. Comparative Characteristics of Possible Isotope Combinations for Regenerative Thermal Neutron Flux Detector

$\begin{array}{llccc}\begin{array}{l}\text { Fertile } \\ \text { Isotope }\end{array} & \begin{array}{l}\text { lalf } \\ \text { Life, } \\ \text { Days }\end{array} & \begin{array}{l}\text { Fissile } \\ \text { Isotope }\end{array} & \frac{\text { Capos }}{\text { Capture }} & \frac{\text { Fission }}{232_{\text {ih }}} \\ 27 & 233_{\mathrm{U}} & \sim 10 & \sim 500 \\ 234_{\mathrm{U}} & & 235_{\mathrm{U}} & \sim 100 & \sim 600 \\ 238_{\mathrm{U}} & 2-1 / 2 & 239_{\mathrm{Pu}} & \sim 10 & \sim 750 \\ 240_{\mathrm{Pu}} & & 241_{\mathrm{Pu}} & \sim 1000 & \sim 950\end{array}$

Detector sensitivity and the details of interelectrode spacing and detector configuration including cable and electrical connectors are shown in Figure 1. The active chamber volume is an annular section about 0.015 in. thick, 0.89 in. diameter, and 1 in. long, furmea by concentric coaxial cylinders supported at each end by ccramic insulators. A limiting factor in the closeness of interelectrode spacing to reduce chamber volume and corresponding gamma sensitivity is posed by voltage breakdown limits. A polarizing potential of plus $200 \mathrm{~V}$ and a $0.015 \mathrm{in}$. spacing is required for efficient charge collection in the chamber. 


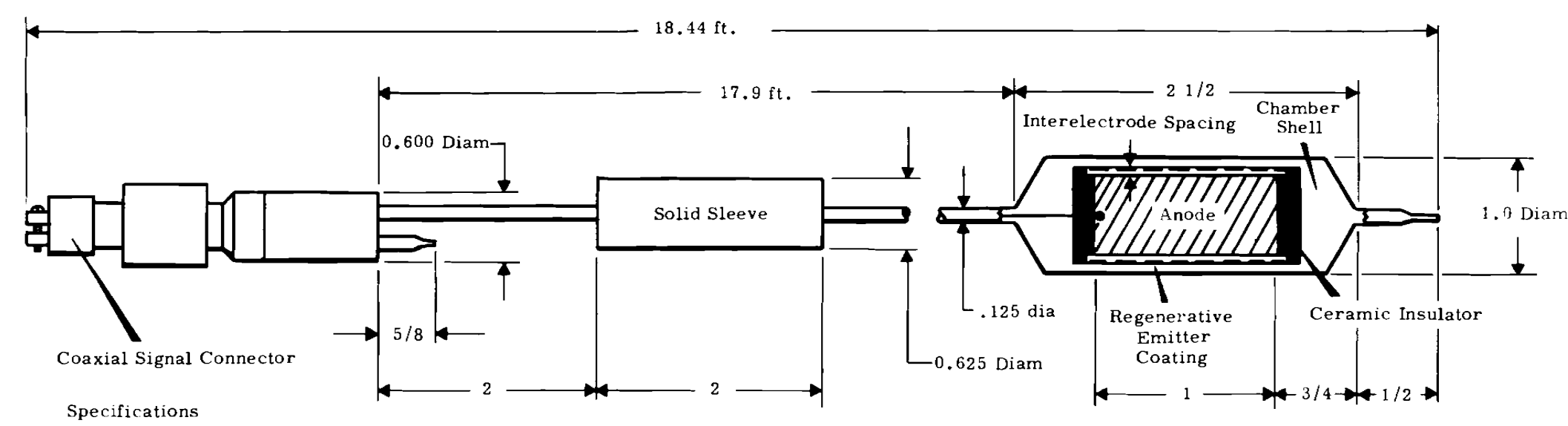

Specifications

Operation:

Neutron Sensitivity - $1 \times \mathrm{x}^{10^{-16}} \mathrm{a} / \mathrm{nv}$ Nominal

Neutron Flux Range - $10^{9}$ to $10^{14}$ nv

Gamma Sensitivity - $8 \times 10^{-13} \mathrm{a} / \mathrm{r} / \mathrm{hr}$ Nominal

Operating Voltage - 100 to $200 \mathrm{VDC}$

Temperature Range - 0 to $40^{\circ} \mathrm{C}$

Pressure Maximum - $500 \mathrm{psig}$
Insulation Resistance $-10^{9} \mathrm{ohms} \mathrm{Min} \mathrm{at} 100 \mathrm{VDC}$ and $70^{\circ} \mathrm{C}$

Sensitive Length

Materials

Cable Sheath - ALSI 304 Stainless Steel

Chamber Shell - AISI 304 Stainless Steel

Cable Insulation - Alumina

Chamber Insulation - Alumina

Filling Gas - Argon at $91.5 \mathrm{~cm}$ Mercury

Cathode - Uranium Coating $\left(10.2 \% \mathrm{U}^{235}, 89.8 \% \mathrm{U}^{234}-18.2 \mathrm{~cm}^{2}\right.$ Active Area)

Active Volume - Annular Region 0.015 in, by 0.89 in. Diam

Weight: 2 lb. Approx.

Neg. PNL-0671976-2

FIGURE 1. Design Details of Experimental In-Core Regenerative Neutron Chamber Sensitive coating material is a uranium isotope mixture in which $234 \mathrm{U}$ transmutes to $235 \mathrm{U}$ to sustain signal strength during in-core exposures to large thermal neutron fluence.) 


\section{TEST CAPSULE}

The two regenerative detectors were mounted in a water cooled test capsule as shown in Figure 2. The capsule featured relatively simple configuration and used proven structual materials as identified. The capsule contains provision for the insertion of a dry cobalt aluminum flux wire for measuring neutron particle fluence and estimating flux levels.

This long slender assembly penetrates the reactor core and locates the test samples in a flat flux region of the core. Numerous support blocks and relatively rugged construction are required in-core to position and hold the experimental chamber firmly and restrain possible motion caused by flow of cooling water. This test capsule firmly positioned the two samples side by side in the reactor core throughout the course of the investigation.

\section{TEST CIRCUITS}

At the start of the tests, the electrical output signals of both chambers were continuously recorded on a strip chart recorder. As shown in the earlier report, (2) a range switch selected the signal developing resistors to match the increases or decreases in the signal output over a four decade current range. Periodically, about twice a month, chamber plateau characteristics and insulation resistance values were measured on both chambers. By using an $x-y$ recorder, a complete saturation curve ( $I-V$ curve) was machine drawn in a few minutes.

The details of the $I-V$ test circuits for accurately and efficiently accumulating this performance data are shown in Figure 3. An $x-y$ recorder simultaneously plots the detector voltage on the abscissa and the corresponding signal current 

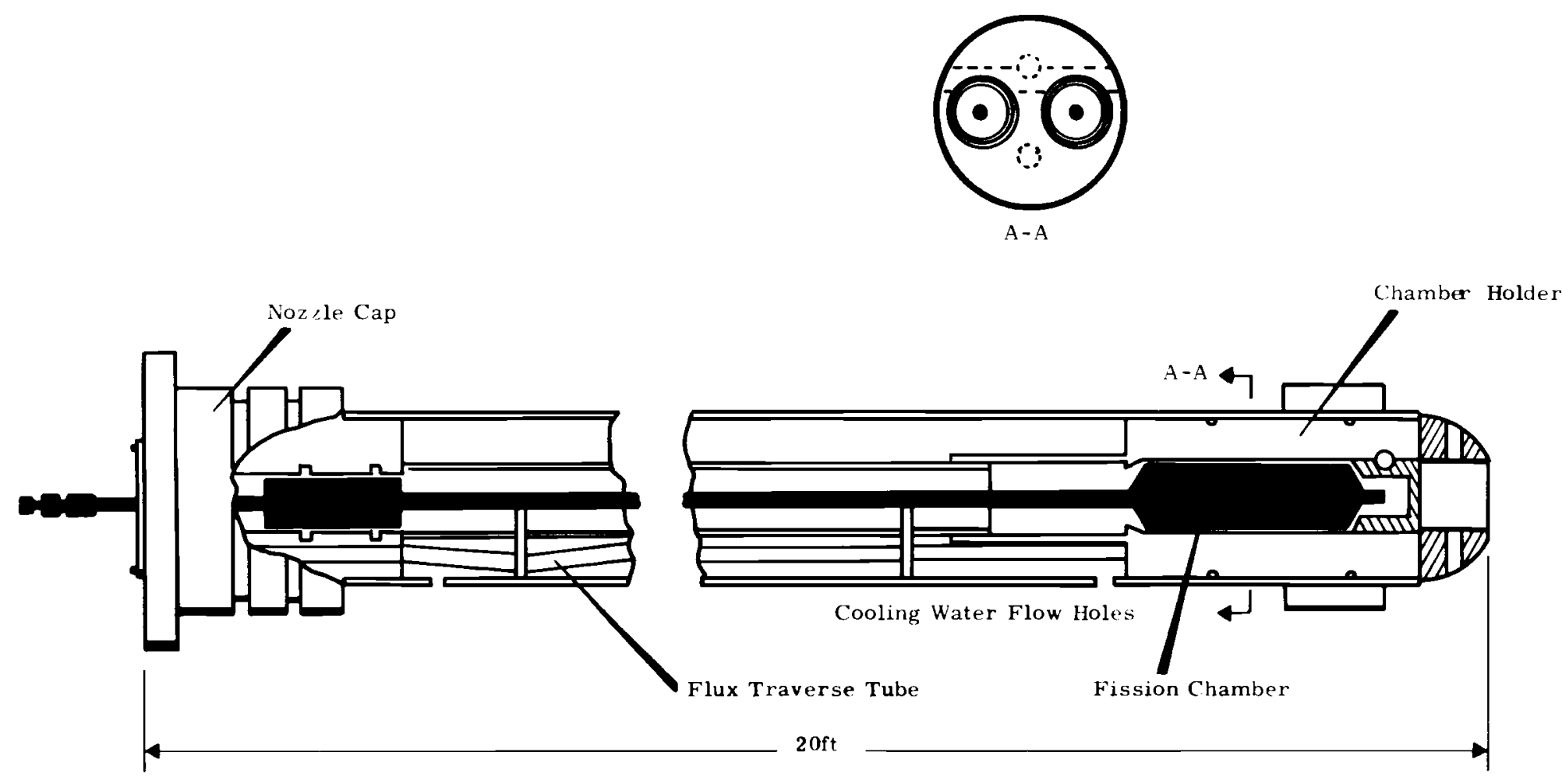

Neg. PNL-0670909-5

FIGURE 2. Regenerative Chamber Test Capsule (This is an instrumented test capsule in which the leads from two chambers are brought out from the reactor core. The integral chamber and lead assemblies are positioned firmly in place by aluminum supports and flow-holes are provided for cooling water. The $0.025 \mathrm{in}$. dry traverse tube permits ready access for insertion of flux measuring wires.) 


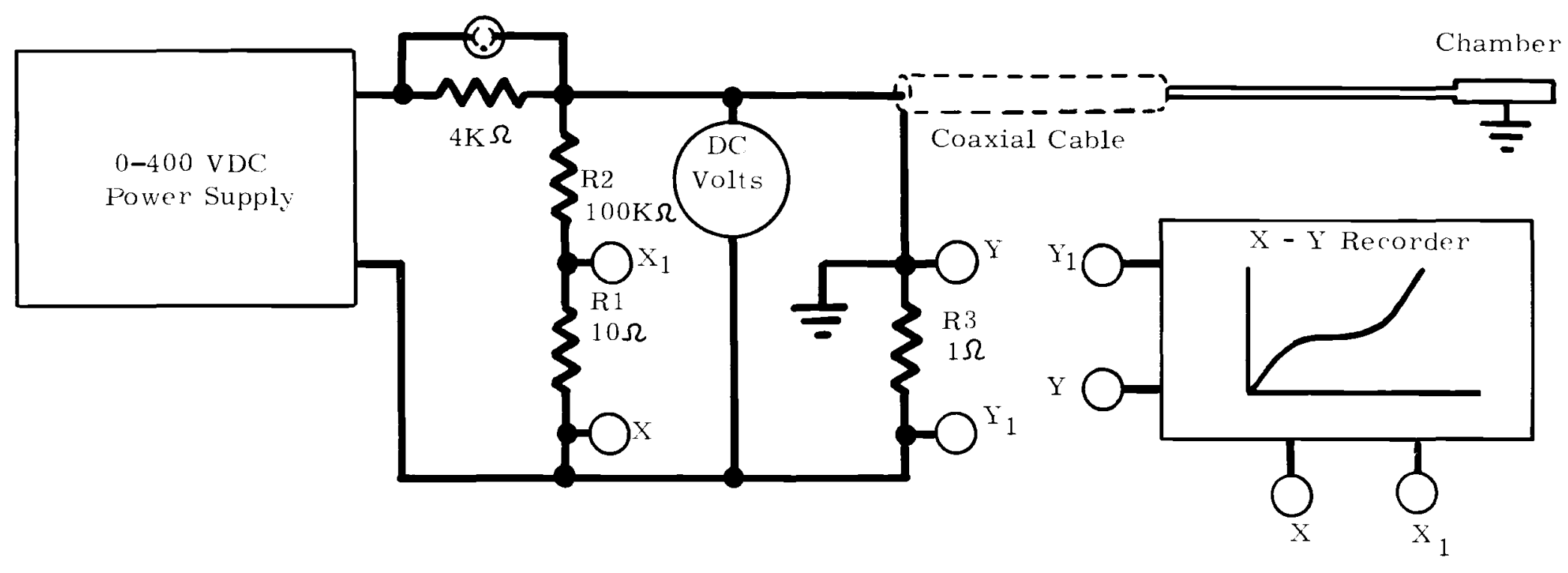


output on the ordinate. A polarizing potential from zero to plus 400 volts is supplied by an adjustable power supply that is highly isolated from circuit ground to prevent leakage current error. Good circuit grounding practices were used to isolate the signal current from possible error-inducing, circulating ground currents. A $4000 \Omega$ current limiting resistor is placed in series with the chamber to protect the chambers against possible short circuits.

\section{EXPERIMENTAL RESULTS}

\section{BURNUP PERFORMANCE}

Constancy of the neutron output signal and comparative theoretical performance characteristics of both a regenerative and a ${ }^{235} \mathrm{U}$ coated chamber as a function of increasing nvt are shown in Figure 4. This signal output data was normalized against reactor coolant temperature change to correct for varitions in reactor power level. Despite this correction a sizable spread $(~( \pm 15 \%)$ in individual data points occurred.. This spread is attributed to unavoidable changes in reactor neutron flux level caused by shifts or oscillations in the flux profile. The regenerative chamber characteristic is a fitted curve (least squares fit) over the $20-70 \times 10^{20} \mathrm{n} \mathrm{cm}^{-2}$ range, and the intervals shown are the $95 \%$ confidence limits on the fitted linear curve. A mathematical test for linearity indicated that no significant departure from the simple relation occurred. Over this exposure range the sensitivity (average of both test samples) decreased with a slope of $-0.373 \pm 0.049 \%$ per $1 \times 10^{20}$ $\mathrm{n} \mathrm{cm}^{-2}$. The anomalous decrease in signal current at the start of the exposure, though similar in character to ${ }^{235_{U}}$ burnup, has not been satisfactorily accounted for and is thought to be not representative to the optimum $10 \%{ }^{234} \mathrm{U}-90 \%{ }^{235} \mathrm{U}$ regenerative emitter. Compared to the ${ }^{235} \mathrm{U}$ curve, the ${ }^{234} \mathrm{U}-{ }^{235} \mathrm{U}$ regenerating chamber characteristic demonstrates a substantially improve constancy of signal output to achieve at least tenfold 


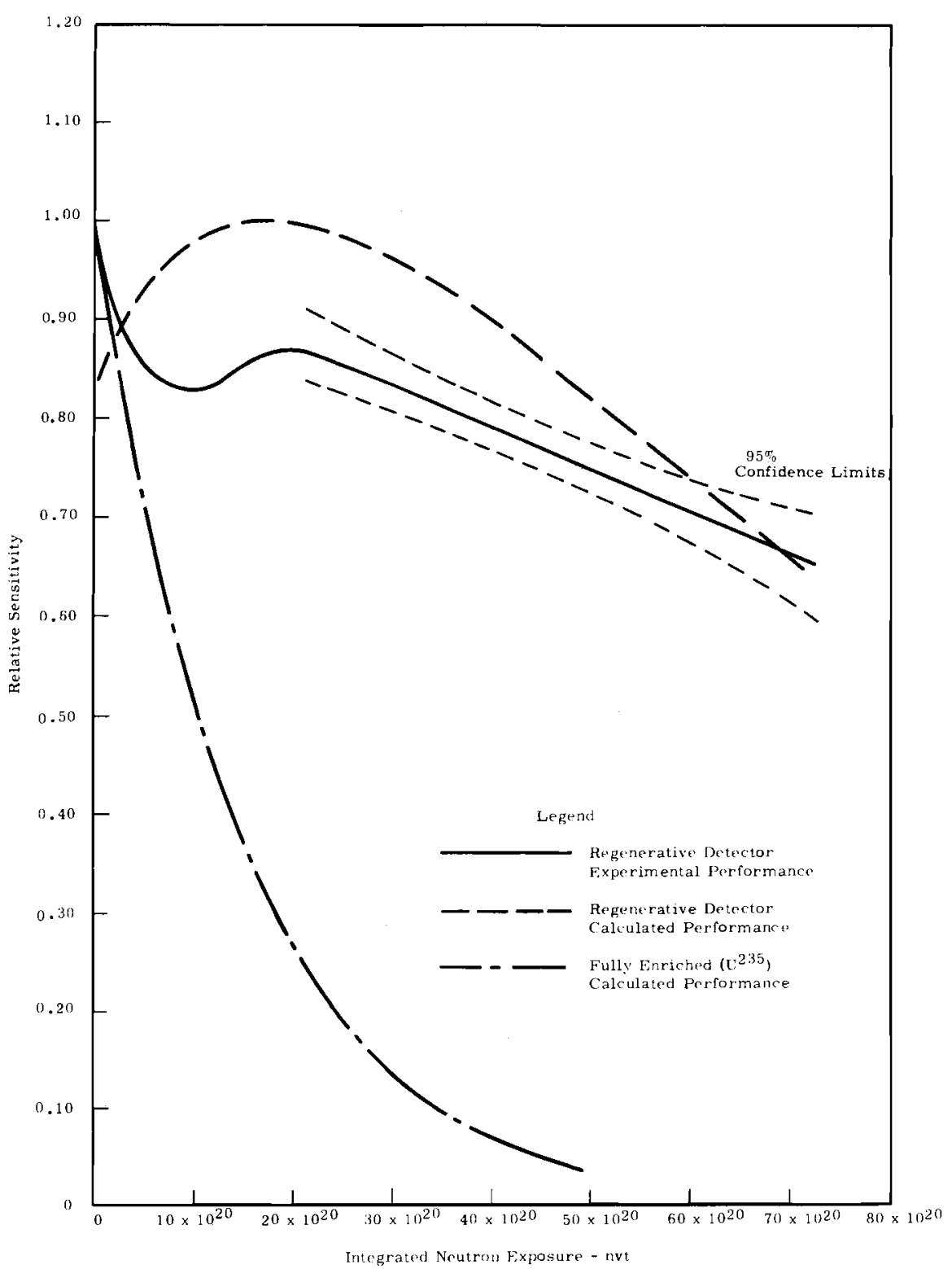

Neg. PNL-0670909-4

FIGURE 4. Effect of In-core Exposure on Chamber Sensitivity 
improvement in useful 1 ife. An exposure of $5 \times 10^{21} \mathrm{nvt}$ is equivalent to ten years operation in a commercial reactor at a flux level of $1 \times 10^{13} \mathrm{nv}$.

\section{CHAMBER DIELECTRIC}

Both regenerative chamber samples experienced a signal strength decrease during the first $1.5 \times 10^{21}$ fluence of the neutron exposure as well as severe degradation of insulation resistance ( $23 \mathrm{X}$ reduction) as shown in Table II. Coupled with the resistance decrease a dielectric breakdown occurred with polarization voltages over a range of 100 to $400 \mathrm{Vdc}$. Interestingly, there occurred a periodic restoration of dielectric strength during each reactor shutdown and by an exposure of $5 \times 10^{21}$ nvt the dielectric strength had been partially restored, as shown in Figure 5. Restoration occurred to the extent that both chamber samples were capable of operation with up to $200 \mathrm{Vdc}$ polarizing potential without a dielectric breakdown occurring. We consider this anomalous behavior to be not typical of the regenerative emitter material and not typical of a fission chamber vehicle of this type. The quality of the seal between the integral cable and chamber is under question and possible migration of gas from the cable mineral insulation ( $\mathrm{MgO}$ ) into the chamber volume proper is postulated as a cause of this anomalous behavior.

\section{PLATEAU CHARACTERISTICS}

Degradation in insulation resistance is also evident in Figure 6. The two upper curves (obtained after substantial in-core exposure) exhibit a high slope characteristic above $100 \mathrm{Vdc}$ indicating a poor chamber dielectric condition. TYPICAL SIGNAL PERFORMANCE

Typical chamber performance, measuring neutron flux level during transient and steady state operation of the nuclear 


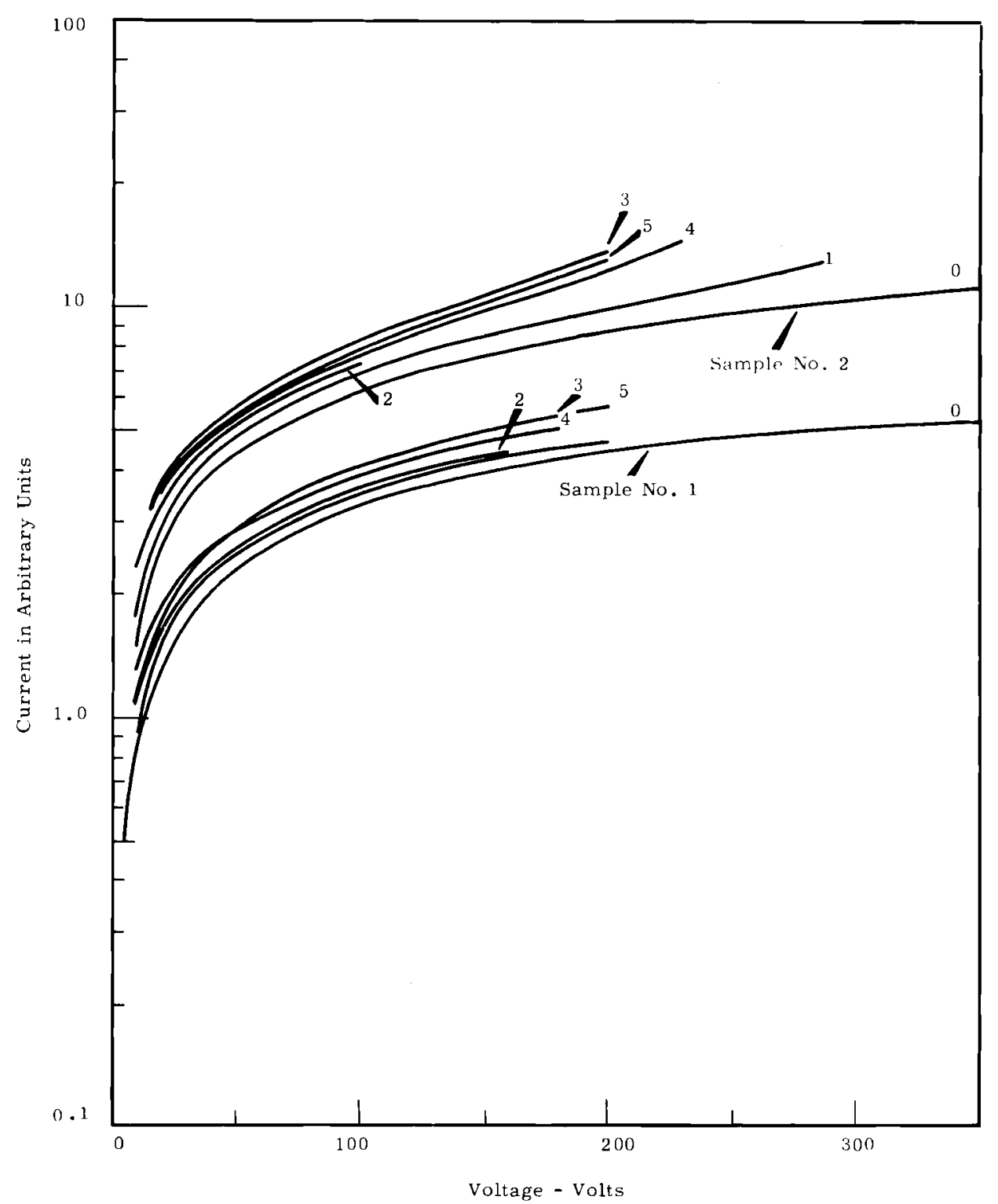

FIGURE 5. Effect of In-core Exposure on Regenerative Chamber Plateau Characteristics (The curves are numbered to indicate time sequence with "O" being the initial detector characteristics. A neutron exposure of about $1 \times 1021$ fluence was incurred between each successive curve. The plateau characteristics tended to stabilize as shown after an exposure of $2 x 1021$ fluence) 


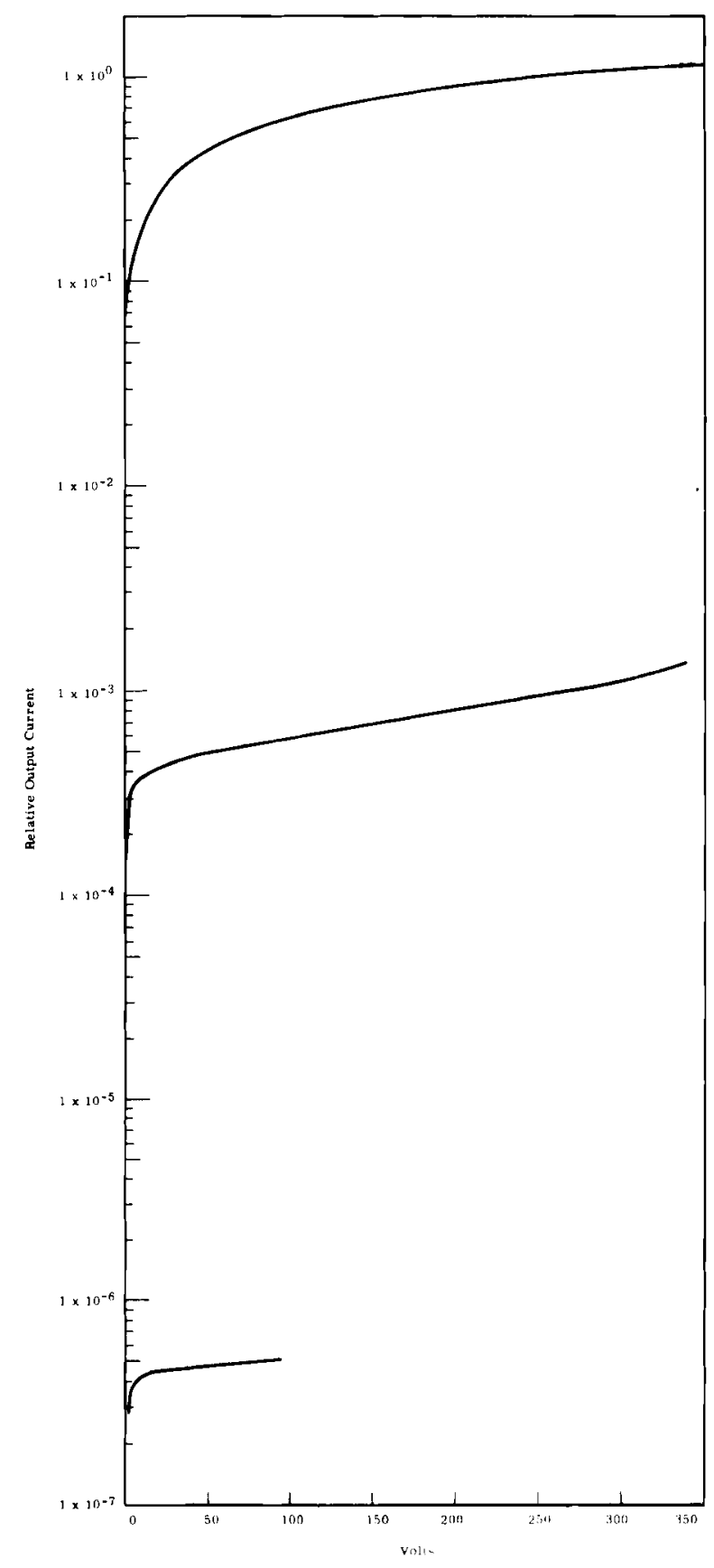

Neg. PNL-0670909-3

FIGURE 6. Typical Saturation Curves 
reactor, are shown in Figure 7 . The recorded signals exhibit prompt proportionate sensitivity for both regenerative chambers.

\section{MALEII. Effects of Sustained In-Core Exposure on Electrical Resistance of Regenerative Neutron Fission Chamber}

\begin{tabular}{|c|c|c|c|c|c|}
\hline \multicolumn{2}{|c|}{$\begin{array}{c}\text { Exposure, } \\
\text { nvt }\end{array}$} & $\begin{array}{c}\text { Relative } \\
\text { Flux } \\
\text { Leve1 } \\
\end{array}$ & \multicolumn{2}{|c|}{$\underset{\Omega}{\text { Samp le }} \# 1$, } & $\underset{\Omega}{\text { Sample }} \# 2$, \\
\hline & 0 & $0 *$ & $1.5 \mathrm{x}$ & $10^{11}$ & $1.1 \times 10^{11}$ \\
\hline & 0 & 0 & 2 & $10^{10}$ & $1.4 \times 10^{10}$ \\
\hline 1.2 & $x \quad 10^{21}$ & 0 & $1.1 \mathrm{x}$ & $10^{9}$ & $1.1 \times 10^{9}$ \\
\hline 0.1 & $\times 10^{21}$ & 1 & 3 & $10^{5}$ & $\times 10^{4}$ \\
\hline 1.5 & $\times 10^{21}$ & 1 & 8 & $10^{4}$ & $2.5 \times 10^{4}$ \\
\hline 3 & $x 10^{21}$ & 1 & 6 & $10^{4}$ & $2.2 \times 10^{4}$ \\
\hline 5 & $\times 10^{21}$ & 1 & 6 & $10^{4}$ & $2.2 \times 10^{4}$ \\
\hline 3 & $x 10^{21}$ & 0.4 & 3 & $10^{5}$ & $\times 10^{5}$ \\
\hline 7 & $\times 10^{21}$ & 1 & 6 & $10^{4}$ & $2.5 \times 10^{4}$ \\
\hline
\end{tabular}

Out of reactor

\section{ADVANCED EXPERIMENTAL REGENERATIVE NEUTRON CHAMBERS}

Preparations are established for a second test capsule that includes a comprehensive package of ten devices. This composite assembly includes four types of chambers: regenerative, a standard $235_{\mathrm{U}}$, an uncoated gamma unit, and two rhodium type devices. Except for the rhodium self-powered units, all chambers are similar in configuration. The type or omission of sensitive emitter material is the principal difference. Al1 chamber configurations are representative of designs that 

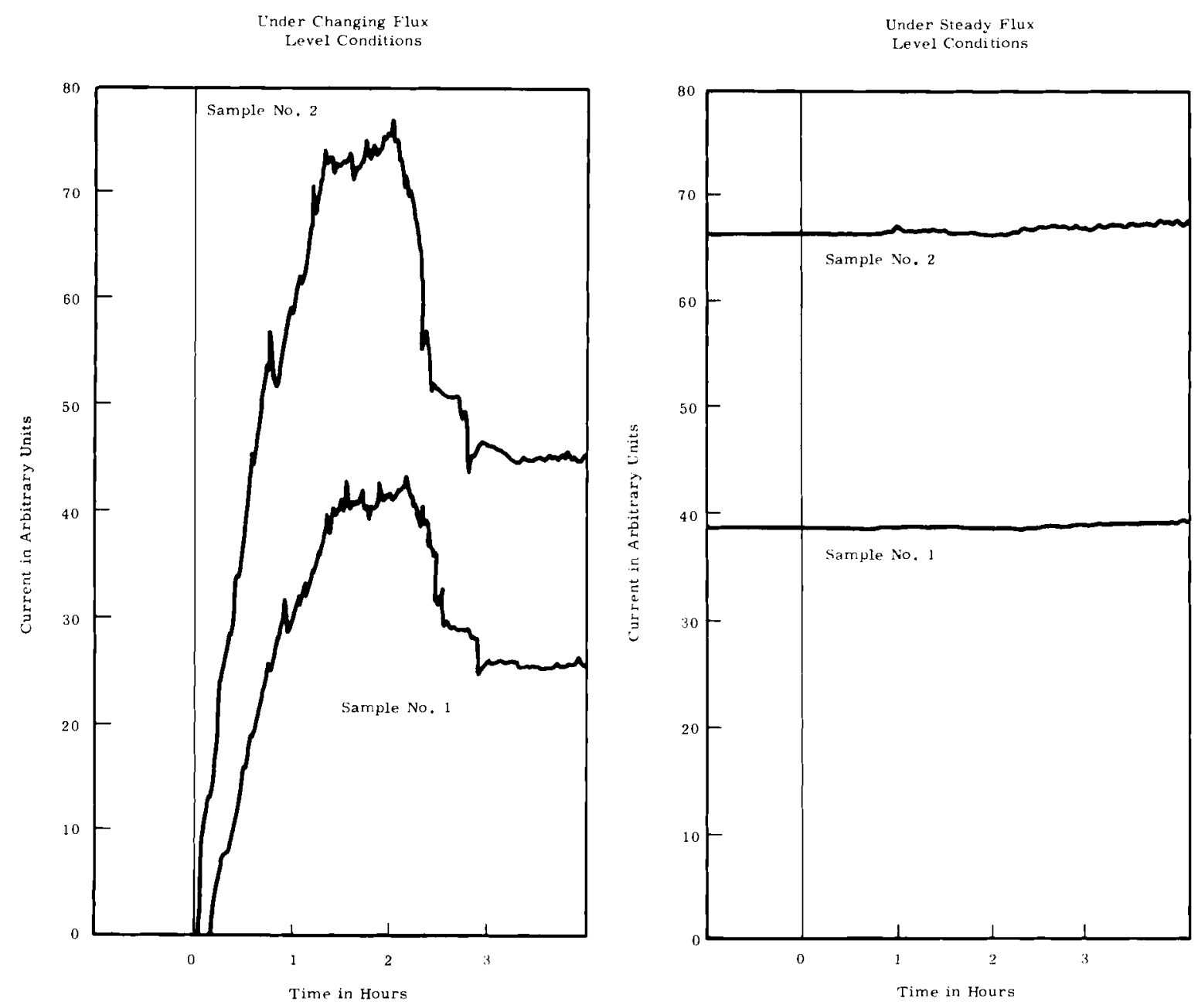

Neg. PNL-0670909-1

FIGURE 7. Typical Regeneration Chamber Recorded Signal output. 
can be obtained from leading detector manufactureres in the nuclear industry. The dimensions of the in-core fission chambers are 0.25 in. (or less) diameter by 3.5 in. (or less) in length, and the regenerative chambers incorporate the optimum regenerative mixture of $10 \%{ }^{235} \mathrm{U}$ and $90 \%{ }^{234} \mathrm{U}$, as did the previous experimental chambers.

To accelerate the in-core life testing of this new capsule, plans are established and approvals granted to conduct the irradiation at the Engineering Test Reactor (ETR). This capsule, irradiated in a neutron flux of $5 \times 10^{14} \mathrm{nv}$, will provide an excellent source of accelerated comparative performance data. Hermetic seals are incorporated between the integral cables and chamber assemblies to prevent gas migration into the sensitive chamber volume. These prototype units will provide improved statistical data for establishing the performance of the regenerative emitter material and also provide needed additional information about chamber insulation and dielectric characteristics. Concurrent measurements of all ten chambers will be made for neutron sensitivity, response time, and dynamic range. This composite test arrangement will provide an excellent comparison of performance characteristics for the various types of chambers operating under nearly identical in-core conditions.

\section{ACKNOWLEDGEMENT}

The contributions of co-workers L. D. Philipp, W. L. Bunch, M. R. Wood and J. I. Forsberg during the various phases of the described work are gratefully acknowledged.

\section{BIBLI OGRAPHY}

1. J. W. Hilborn. "Self-Powered Neutron Detectors for Reactor Flux Monitoring," Nucleonics, vol. 22, February 1964.

2. W. L. Bunch and $M . R$. Wood. Initial Operating Characteristics of Regenerating In-Core Neutron Chambers, BNWL-14, Pacific Northwest Laboratory, Richland, Washington, January 1965. 
3. W. L. Bunch. Regenerating Detecting Techniques for Reactor Neutron Fiux Monitoring, HW-81986, May 1964.

4. D. E. Hegberg. Feasibizity Study of In-Core Neutron Flux Monitoring with Regenerating Detectors, HW-73335, June 1962.

5. W. L. Bunch. "Technique for Optimizing the Composition of Regenerating-Neutron-Flux Monitors," Nuclear Applications, vol. 1, June 1965.

6. W. R. Loosemore and J. A. Dennis. "The Continuous Measurement of Thermal-Neutron Flux Intensity in High-Power

Nuclear Reactors, J. Brit. Nuclear Energy Conf. April 1962. 


\section{DISTRIBUTION}

Number of

Copies $\underline{\text { AEC Division of Technical Information Extension }}$

AEC Division of Technical Information Extension

UK/U.S. Fast Reactor Exchange (12)

EURATOM/U.S. Fast Reactor Exchange (35)

AEC Library, Washington

Division of Reactor Development Technology

R. E. Feit

N. Grossman

F. C. Legler

G. E. Poyet

AEC Richland Operations Office

C. L. Robinson

R. K. Sharp

Technical Information Library

AEC, RDT Site Representative - PNL

W. E. Fry

P. G. Holsted

A. G. Hosler

Atomic Energy of Canada, Limited, Pinawa, Manitoba

J. W. Hilborn

Argonne National Laboratory

A. Amorosi

J. M. Harrer

Douglas United Nuclear, Inc.

T. W. Ambrose

A. E. De Mers

G. C. Fullmer

N. T. Hildreth

J. E. Kaveckis

M. C. Leverett

W. S. Nechodom 
Number of

Copies

47
Batte11e-Northwest

E. R. Astley

T. R. Billeter

D. P. Brown

W. L. Bunch

R. G. Clark

D. L. Condotta

R. R. Cone

G. M. Dalen

G. E. Driver

J. I. Forsberg

G. F. Garlick

D. L. Hovorka

C. E. Huck

C. N. Jackson

R. E. Nightingale

R. S. Paul

L. T. Pedersen

L. D. Philipp

J. T. Russe11

J. C. Spanner

W. G. Spear

C. D. Swanson

M. R. Wood

F. W. Woodfield

D. C. Worlton

Technical Publications

Technical Information Files 